LETTERS I BOOKS I POLICY FORUM | EDUCATION FORUM I PERSPECTIVES

\title{
LETTERS
}

\section{Factory Flies Are Not Equal to Wild Flies}

IN HIS NEWS FOCUS ARTICLE "WELCOME TO ETHIOPIA'S FLY FACTORY" (20 July, p. 310), Martin Enserink highlights the controversy generated by the use of the sterile insect technique (SIT) and its application for controlling and eradicating tsetse (Glossina spp.) in Africa. Although it is clear that SIT has a history of successes and failures, and has both champions and critics, much of the focus, especially in this discussion, is on costs and benefits from the social and political perspectives and the problems posed by a multitude of tsetse species. We agree that such a focus is useful and necessary, but it is not sufficient.

A major avenue of concern receiving scant attention in Enserink's article, and one that will have major implications for Ethiopia's eradication plan, is laboratory adaptation of the flies.

The compatibility and competitiveness of laboratory-reared tsetse for release into wild populations are concerns that have been raised previously in behavioral (1) and physiological work $(2,3)$. Substantial differences are typically found between natural populations and colony-reared flies, ranging from physiological tolerance of lethal temperatures to mating compatibility. Moreover, feeding behavior in tsetse appears to be a learned response obtained during early adult development (4), suggesting that laboratory-reared flies raised on artificial membranes may not feed on wild animals. Thus, they would not survive for more than a few days in the wild. Similarly, caged rearing conditions are known to be deleterious to flight and locomotor performance because flight muscle development is restricted, which in turn may limit mating success in the wild (5). Other work on insects has shown that laboratory adaptation substantially alters animal performance (6).

Thus, the SIT program for eradicating tsetse hinges on a crucial and neglected question: the performance capabilities in the wild of flies reared in the laboratory. If colony flies are substantially outperformed by their wild counterparts, which seems likely on present evidence, the SIT program might fail for reasons that have little to do with financial investment, commitment, or species numbers.

JOHN S. TERBLANCHE AND STEVEN L. CHOWN

Centre for Invasion Biology, Department of Botany and Zoology, Stellenbosch University, Stellenbosch 7602, South Africa. E-mail: jst@sun.ac.za

\section{References}

1. ]. Brady, A. ]. Crump, Physiol. Entomol. 3, 177 (1978).

2. J. S. Terblanche et al., Am. J. Trop. Med. Hyg. 74, 786 (2006).

3. P. Taylor, Physiol. Entomol. 2, 317 (1977).

4. J. Bouyer et al., Biol. Lett. 3, 113 (2007).

5. E. Bursell, Proc. R. Entomol. Soc. London 36A, 69 (1961).

6. A. A. Hoffmann et al., Evolution 55, 1621 (2001).

\section{Promoting Science and Technology from the Top}

GOVERNMENTS IN DEVELOPING COUNTRIES are the primary source of resources and guidance for science and technology (S\&T). Despite an apparent recognition of the importance of S\&T for socioeconomic growth and poverty reduction (as shown by a modicum of investment), the full benefits of S\&T have not been achieved. Chief among the reasons for this are (i) lack of political vision and will, (ii) low business confidence in S\&T and innovation, (iii) imprecise decision-making and archaic management, (iv) suboptimal investments, (v) national inertia and illiteracy, (vi) puerile dependency, (vii) a lack of imagination, and (viii) corruption.
S\&T are tools that motivate, propel, and dictate change, which often demands incisive administrative management and cultural shifts of varying degrees. S\&T may threaten ministries jostling for power. Furthermore, bureaucracy is steeped in the orthodoxy of seniority and political favoritism and tends to be uncritically rigid and suspicious of fresh intellectual talent. Changes in management structures and methods, decision-making, implementation, and reviews of effectiveness and coordination are often stoutly resisted.

Consequently, national S\&T management bodies and coordinating systems that are installed to implement policies and execute plans often prove ineffectual. Strong political leadership at the top of the S\&T structure is needed. Prime ministers or presidents should take charge.
The decision to have prime ministers or presidents lead the knowledge transfiguration of a country will circumvent unnecessary layers of government, while quelling political rivalries. Additionally, the private sector needs assurance and accessible incentives from government to support research and development (R\&D) and thereby create new businesses, jobs, and skills. The top levels of government must make the necessary budgetary decisions to support local R\&D, which has, until now, been left to the whims and fancies of foreign technical assistance and investment. It is very difficult for ministers of finance and other cabinet officers to allocate funds to seemingly intangible S\&T development when there is pressure on the budget to satisfy immediate and pressing needs like education, health care, and roads. Science and technology courses 
specifically designed to educate top political leaders regarding the long-term benefits are therefore necessary.

The ultimate challenge is to convince busy prime ministers and presidents to take charge of these efforts. This is where national S\&T advisors are vital.

ARNOLDO K. VENTURA

Special Science and Technology Advisor to the Prime Ministe of ]amaica, Office of the Prime Minister, Kingston 6, Jamaica.

\section{How Old Is the Human Presence on Cyprus?}

ALBERT AMMERMAN'S CONTRIBUTIONS TO archaeology are substantial, but his comments about Cyprus may mislead the reader ("Exploring the prehistory of Europe, in a few bold leaps," J. Bohannon, News Focus, 13 July, p. 188). Current studies on this Mediterranean island have indeed indicated a human presence much earlier than previously believed. As the article notes, research by Peltenburg and others has pushed back the island's Neolithic presence to $\sim 8200$ calibrated B.C.E.

Ammerman suggests that his sites are approximately 12,000 years old and are the remains of seafaring pre-Neolithic hunters and gatherers. Whether or not aeolianite dunes would have made suitable camps, we commend Ammerman for examining ephemeral sites that all too often have been ignored. However, he believes that these are "the oldest evidence of seafaring in the Mediterranean," a claim presently based only on artifactual data, and as Peltenburg points out, "independent evidence" is needed to confirm their antiquity.

An early human presence on Cyprus has been well established at Akrotiri Aetokremnos for nearly two decades (1). It is thus no surprise that there may be other sites dating to this time period, and many of us hope that Ammerman's sites are as old as he claims. But until this can be confirmed by defensible dating of materials in good context, these sites should not enter the literature as examples of a pre-Neolithic presence on Cyprus.

ALAN H. SIMMONS ${ }^{1}$ AND ROLFE D. MANDEL ${ }^{2}$

${ }^{1}$ Anthropology and Ethnic Studies, University of Nevada, Las Vegas, 4505 Maryland Parkway, Las Vegas, NV 89154, USA. ${ }^{2}$ Kansas Geological Survey, University of Kansas, Lawrence, KS 66047, USA.

\section{Reference}

1. A. Simmons, Faunal Extinction in an Island Society (Klewer/Plenum, New York, 1999). 


\section{Ethics and Refinement in Animal Research}

SCIENTISTS AND JOURNALS COULD AND should do more to secure the ethical standards of animal use in biomedical research. Scientists often justify animal use by referring to the scientific value and biomedical importance (1). However, except from a purely anthropocentric perspective, ethical concerns about compromised animal welfare cannot be eased by human benefits alone (2). It is equally important that the benefits are achieved with a minimum of negative effects to the animals involved. Thus, scientists must apply "refinement," the third $\mathrm{R}$ of the so-called 3 Rs (3). But scientists sometimes seem to do less than they should, and journals fail in their duty to enforce high ethical standards.

We studied the use of animals as models for Huntington's disease. In this model, refinement should focus on limiting the negative impact of declining sensorimotor function as the neurodegenerative disease progresses: Housing adaptations facilitating food and water intake and humane endpoints (using earlier, less severe clinical signs as endpoint parameters rather than awaiting spontaneous death) are two possible approaches (4). We asked to what extent animal welfare problems and refinements addressing them were reported in publications of the most common rodent models by analyzing 90 research reports published in international peer-reviewed journals during 2003-04. These include quinolinic acid $(5,6)$ and 3-nitropropionic acid $(6,7)$ administration to rats and mice and R6/1, R6/2, and N171-82Q transgenic mice (8-10). Our results show that the majority of experiments (53) were in the two most severe categories, in which animals have sensorimotor deficits interfering with their capacity to eat and drink normally from the cage top. Very few papers reporting such severe experiments included information on refinement measures: Out of 14 survival studies of transgenic animals with a progressive neurodegenerative phenotype, only 6 referred to humane endpoints and only 2 to housing adaptations. Among the majority of studies referring to compliance with official regulations and/or efforts to reduce animal suffering, we also found experiments using far from best practices, such as administration of rising neurotoxin doses until high animal mortalities were reached.

Journals should ensure that referees seriously consider whether submitted studies were indeed carried out with the smallest achievable negative impact on the animals. Although important results might be found in a paper not complying with current refinement standards, a journal like Science should still reject such a paper, thereby sending an important signal to the research community, similar to what is common practice for studies involving human research subjects. Furthermore, journals should give authors space to describe refinement and welfare precautions. We demonstrate that such descriptions are rare, which means that other researchers cannot benefit from refinement ideas (11), in turn implying a real danger that animals will have to suffer unnecessarily, and that animal welfare will be improved later than necessary. I. ANNA S. OLSSON, ${ }^{1,2}$ AXEL K. HANSEN, ${ }^{3}$ PETER SANDøE ${ }^{2}$

${ }^{1}$ Laboratory Animal Science, IBMC-Instituto de Biologia Molecular e Celular, Universidade do Porto, Rua do Campo Alegre 823, 4150-180 Porto, Portugal. 2Danish Centre for Bioethics and Risk Assessment, Faculty of Life Sciences, University of Copenhagen, Rolighedsvej 25, 1958 Frederiksberg C, Denmark. ${ }^{3}$ Division of Laboratory Animal Science and Welfare, Faculty of Life Sciences, University of Copenhagen, Dyrlaegevej 88, 1870 Frederiksberg C, Denmark.

\section{References and Notes}

1. E. Frankel Paul, ]. Paul, Eds., Why Animal Experimentation Matters: The Use of Animals in Medical Research (Transaction Publishers, New Brunswick, N], 2000).

2. I. A. S. Olsson, P. Robinson, K. Pritchett, P. Sandøe, in Handbook of Laboratory Animal Science, G. Van Hoosier, J. Hau, Eds. (CRC Press, Boca Raton, FL, ed. 2, 2002), pp. 13-30.

3. W. M. S. Russell, R. L. Burch, The Principles of Humane Experimental Technique 1959/1992 (http://altweb.jhsph. edu/publications/humane_exp/het-toc.htm).

4. D. B. Morton, ]. Hau, in Handbook of Laboratory Animal Science, G. Van Hoosier, ]. Hau, Eds. (CRC Press, Boca Raton, FL, ed. 2, 2002), pp. 457-486.

5. M. F. Beal et al., Nature 321, 168 (1986).

6. E. Brouillet, F. Condé, M. F. Beal, P. Hantraye, Prog. Neurobiol. (Oxf.) 59, 427 (1999).

7. E. Brouillet et al., J. Neurochem. 60, 356 (1993).

8. L. Mangiarini et al., Cell 87, 493 (1996).

9. E. Hockly, B. Woodman, A. Mahal, C. M. Lewis, G. Bates, Bn Res. Bull. 61, 469 (2003).

10. G. Schilling et al., Hum. Mol. Genet. 8, 397 (1999).

11. H. Würbel, Nature 445, 357 (2007).

12. We thank colleagues in the COST Action B24 Laboratory Animal Science and Welfare; researchers N. Dantuna, C. Maynard, C. Kosinski, E. Diguet, D. Emerich, and H. H. Phuc Nguyen, who provided information on clinical signs in different models; and P. Robinson, who commented on a previous version of the Letter. Preparation of this Letter was part of the interdisciplinary project Comparative Genomics of Man and Pig, funded by the Danish Agency for Science, Technology and Innovation.

\section{Letters to the Editor}

Letters ( 300 words) discuss material published in Science in the previous 3 months or issues of general interest. They can be submitted through the Web (www.submit2science.org) or by regular mail (1200 New York Ave., NW, Washington, DC 20005, USA). Letters are not acknowledged upon receipt, nor are authors generally consulted before publication. Whether published in full or in part, letters are subject to editing for clarity and space. 


\section{CORRECTIONS AND CLARIFICATIONS}

Editors' Choice: "Timing is everything" (31 August, p. 1147). The phrase "...HPV clearance rates-measured as cell-mediated immunity to the virus-were comparable..." should have read "...HPV clearance rates-a measure of cell-mediated immunity to the virus-were comparable..."

Newsmakers: "Indelible" (10 August, p. 731). George Cotzias's name was misspelled in the story.

Policy Forum: "Critical assumptions in the Stern Review on climate change" by W. Nordhaus (13 July, p. 201). On page 202, part of reference 7 was incorrect; the complete reference is K. J. Arrow et al., Climate Change 1995-Economic and Social Dimensions of Climate Change, ]. Bruce, H. Lee, E. Haites, Eds. (Cambridge Univ. Press, Cambridge, 1996), pp. 125-144.

Policy Forum: "Taking science out of the box-foresight recast" by D. A. King and S. M. Thomas (22 June, p. 1701). The URL in reference 6 is incorrect. It should be www. discoverysoftware.co.uk/FloodRanger.htm.

Perspectives: "Nuclear actin as choreographer of cell morphology and transcription" by J. I. Wu and G. R. Crabtree (22 June, p. 1710). The surname of the second author, while correctly spelled in print and in the online article display, was initially spelled incorrectly in the electronic metadata associated with the online article, which led to an incorrect spelling in the electronic table of contents and in online search results, as well as in some indexing services not affiliated with Science. The metadata have been corrected; the proper spelling of the second author's surname is Crabtree.

Reports: "Structure of the multidrug transporter EmrD from Escherichia coli" by Y. Yin et al. (5 May 2006, p. 741). On page 744, following the sentence "In addition, certain singlesite mutations in the cytoplasmic halves...," only reference 17 should be cited. In Fig. 2C, residue EmrD T128 should be EmrD T119 (and the "+" over the corresponding MdfA A137 shifted to MdfA A128 in fig. S1). Finally, the asterisk denoting residue MdfA A324 in fig. S1 was misformatted and should lay over MdfA Y323. The corrected figure has been added to the Supporting Online Material for the Report (see www.sciencemag. org/cgi/data/312/5774/741/DC1/1). The implementation of these corrections does not change the proposed mechanism, as the shifted residues still fall within the boundaries of the proposed selectivity filter.

\section{TECHNICAL COMMENT ABSTRACTS}

\section{Comment on "Organics Captured from Comet 81P/ Wild 2 by the Stardust Spacecraft"}

\section{Maegan K. Spencer and Richard N. Zare}

Sandford et al. (Reports, 15 December 2006, p. 1720) reported on organic compounds captured from Comet 81P/Wild 2 by the Stardust spacecraft. We emphasize the difficulty in assigning the origin of compounds detected diffusely along particle impact tracks and show that rapid heating of aerogel that has never been exposed to cometary particle capture can generate complex aromatic molecules from low-mass carbon impurities present in the aerogel.

Full text at www.sciencemag.org/cgi/content/full/317/5845/1680c

\section{Response to Comment on "Organics Captured from Comet 81P/Wild 2 by the Stardust Spacecraft"}

\section{Scott A. Sandford and Donald E. Brownlee}

Caution must be taken in interpreting measurements of organics in Stardust samples. In particular, as noted in Sandford et al. and reinforced in the comment by Spencer and Zare, one component of Stardust organics, the low-mass polycyclic aromatic hydrocarbons seen diffusely along track surfaces, should be treated cautiously because they may be due to impact conversion of aerogel carbon.

Full text at www.sciencemag.org/cgi/content/full/317/5845/1680d 